www.jmscr.igmpublication.org

Impact Factor 5.84

Index Copernicus Value: 71.58

ISSN (e)-2347-176x ISSN (p) 2455-0450

crossref DOI: _https://dx.doi.org/10.18535/jmscr/v5i9.116

Journal Of Medical Science And Clinical Research

IGM Publication

An Official Publication of IGM Publication

\title{
Influence of Socioeconomic and Demographic Factors on Diabetic Retinopathy
}

\author{
Authors \\ Ranjini Kotancheri, Arun Kumar Ayoor, Karthika P Jayan, Swathi Karuppali \\ Anu Bhaskar
}

Department of Ophthalmology, Government Medical College, Kozhikode, Kerala India, Pin 673008

Corresponding Author

Dr Arun Kumar Ayoor

Professor of Ophthalmology, Govt Medical College, Kozhikode, Kerala India Pin 673008

Email: aruntkr@gmail.com,Telno.9447286310

\begin{abstract}
Introduction: Diabetes mellitus is fast emerging as a pandemic with its impact on the health system of the nation and the economic status of the patient. The ways by which the socioeconomic and demographic factors influence the progression of the disease and its vision threatening complication like retinopathy is still unclear. As these factors play a pivotal role in the management, we have undertaken this study to analyse the effects of them on the disease.
\end{abstract}

Methods: This cross sectional study was conducted among 257 diabetic patients attending ophthalmology department and data about the socioeconomic status, occupation, body mass index, place of residence and severity of diabetic retinopathy were collected and analysed.

Results: Out of 257 patients, 50.2\% were males and $49.8 \%$ females with $77.8 \%$ from rural areas, $35.8 \%$ in the age group of 51-60 years.146 belonged to unemployed group 32 employed in gulf,57 skilled and 22 unskilled. Majority belonged to middle class families $70.4 \%$ ( $p$ value 0.022).Association of body mass index with retinopathy and Clinically Significant Macular Edema (CSME) with socioeconomic status showed insignificant correlation ( $p$ value 0.136).

Conclusion: Socioeconomic and demographic factors influence the development and progression of diabetic retinopathy. Greater severity of retinopathy was observed in the deprived classes of society and also among the rural population. Hence measures to adopt health policies to overcome the barrier of socioeconomic disparity in the availability of treatment and follow up should be implemented at the earliest to reduce sight threatening complication like retinopathy in the lower strata of the society.

Keywords: socioeconomic status, diabetic retinopathy, occupation, body mass index, rural, clinically

Significant macular edema.

\section{Introduction}

Diabetes mellitus is a global public health problem accounting for the major share of morbidity and mortality in the developing nations. The supposed increase of the disease burden from the years 1995 to 2025 was estimated to be $170 \%$ in these nations. ${ }^{(1)}$

As it is a progressive disease requiring lifelong medical care and prompt follow up for the prevention of its varied end organ complications, access to good advice and effective health care 
forms a priority for patients who need to reduce these risks, including the threat to vision. The main aim of medical care is to help reduce bloodsugar levels and other co morbidities so that detection and treatment of complications can be pursued at an earlier stage. Hence delay in early diagnosis of diabetes, long after the onset of the disease, means that more than one-third of them would have already developed evidences of end organ or tissue damage when diagnosed. And this holds true especially in the context of diabetic retinopathy, where advanced stages leave the patient literally blind which could have been prevented if treatment was initiated at the earliest.

Requirements for controlling diabetes mellitus includes a combination of treatment and preventive action. Since diabetes is a multiorgan disease where key role is played by the lifestyle and personal dietary factors, the influence of environmental and socioeconomic variables in the progression of disease has to be emphasised .These include the age, lifestyle, income, accessibility to health care, awareness of the disease and its complications and psychological factors like motivation for receiving treatment and adherence to the lifelong treatment protocols.

It was estimated that 1.5 million people died in the world in 2012 due to diabetes and its complications and among that more than $80 \%$ of the deaths occurred in lower and middle income groups. ${ }^{(2)}$ Though in literature, studies on the effect of diabetes per se on socioeconomic factors were available, fewer were obtained pertaining to the role of socioeconomic factors on the severity of retinopathy. Hence this study was undertaken to evaluate the effects which demographic and economic factors would have on diabetic retinopathy.

\section{Methods and Materials}

This cross sectional study was conducted among 257 type 2 Diabetes Mellitus (DM) patients attending ophthalmology outpatient department at a tertiary health centre during period of 12 months from June 2012 to May 2013 after getting approval from institutional research committee and ethical clearance. An informed written consent was taken from each patient before participation in the study

\section{Inclusion criteria}

Type 2 diabetic patients of the age group 30 to 85 years

\section{Exclusion criteria}

Patients with other retinal pathologies like vascular occlusions, optic atrophy and whose retinal examination was not possible due to hazy media or inadequate dilatation or non cooperative patients.

Pregnant and lactating women, those on oral contraceptive pills, steroids, and dysthyroid patients were also excluded from the study..

\section{Data collection}

A complete analysing validated questionnaire in their regional language was given to the patient and the data of all the patients were collected and analysed. Illiterate patients were explained regarding the study and required details were collected from them. The parameters studied were occupation, socioeconomic status, BMI and place of residence. Participants were categorised into different groups based on occupation into house wife/unemployed, employed in gulf countries, skilled and unskilled personals.

The socioeconomic status of all cases were analysed by taking into account their income, education and occupation and grouped as lower class, middle class and upper class.

Body mass index of each patient was calculated using quetelet formula and was categorised into underweight, normal, overweight and obese.

Comprehensive systemic and ocular examination was done including slit lamp and ophthalmoscopic evaluation. Grading of diabetic retinopathy was done using direct, indirect ophthalmoscope and 90 D and graded based on ETDRS classification. Best corrected visual acuity for distance and near were also obtained.

Blood investigations were done and results recorded. This included complete blood count, blood sugar, fasting lipid profile, renal function test and urine analysis. 


\section{JMSCR Vol||05||Issue||09||Page 28065-28071||September}

\section{Statistical analysis}

Statistical analysis were performed using SPSS Version.17.0 (SPSS ,Chicago, Illinois, USA) software and Chi square test was used do compare the variables.

\section{Results}

We have studied 257 diabetic persons and their socioeconomic status, body mass index and the relation between rural and urban population was studied.

Of 257 participants 129 (50.2) were males and 128 (49.8) were females.35.8\% of the patients belonged to an age group of 51-60years.

Fig 1. Age distribution of the sample

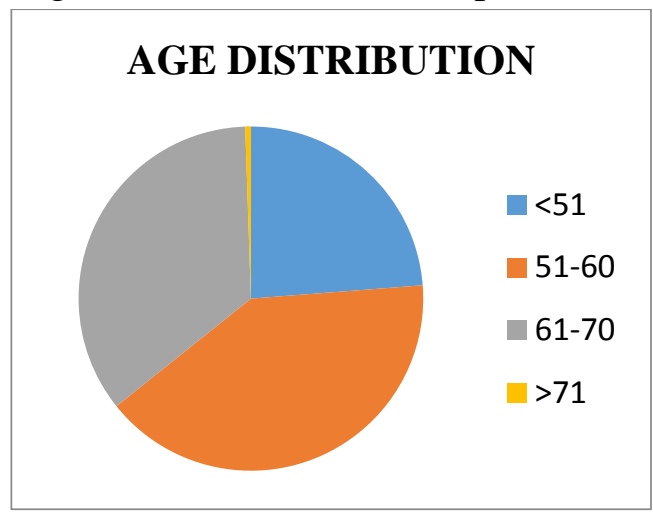

On analysing the occupation of all participants, it was found that 146 of them belonged to unemployed or house wives,32 were employed at gulf and 57 were doing skilled jobs and the remaining were performing unskilled jobs.

The maximum number of patients belonged to middle class families 181 (70.4\%). The participants belonging to the upper class were $54(21 \%)$ and lower class were $22(8.6 \%)$

Fig 2. Classification of sample according to socioeconomic status

\section{SOCIOECONOMIC STATUS}

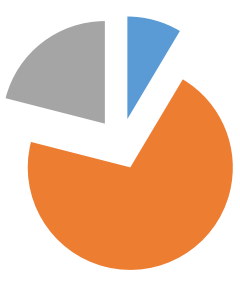

- LOWER CLASS

MIDDLE CLASS

- UPPER CLASS
Chi square analysis of diabetic retinopathy with socioeconomic status was done and a $\mathrm{p}$ value of.022 was obtained which showed a significant association between diabetic retinopathy and middle class family.

Table 1: Body Mass Index and CSME

\begin{tabular}{|c|c|c|c|}
\hline BMI & $\begin{array}{c}\text { NO } \\
\text { CSME }\end{array}$ & CSME & TOTAL \\
\hline UNDERWEIGHT & 39 & 10 & 49 \\
\hline NORMAL & 110 & 57 & 167 \\
\hline OVER WEIGHT & 21 & 12 & 33 \\
\hline OBESE & 8 & 0 & 8 \\
\hline TOTAL & 178 & 79 & 257 \\
\hline
\end{tabular}

On assessing the body mass indices of all participants, $167(64.9 \%)$ persons are having normal BMI. On analysing, the p value was 0.136 which showed an insignificant association with retinopathy.79 of them had clinically significant macular edema which accounted for around $30.7 \%$ of the total subjects and among which majority $(36.4 \%)$ were included in the overweight group.

Of all the 257 cases 200 (77.8) belonged to rural area of residence whereas 57 (22.2) of them belonged to urban areas which showed a positive impact of rural residence on diabetic complications.

Fig 3. Distribution of patients based on place of residence.

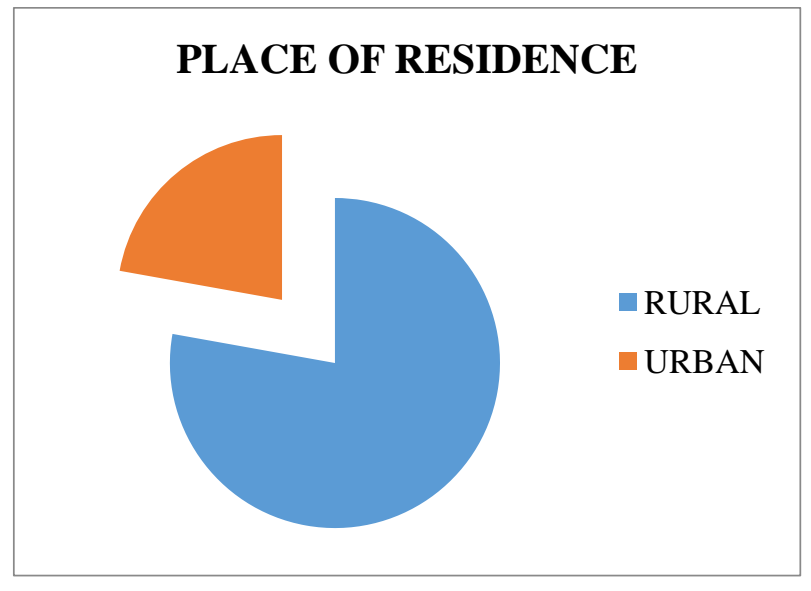




\section{JMSCR Vol||05||Issue||09||Page 28065-28071||September}

Fig 4. CSME with Occupation

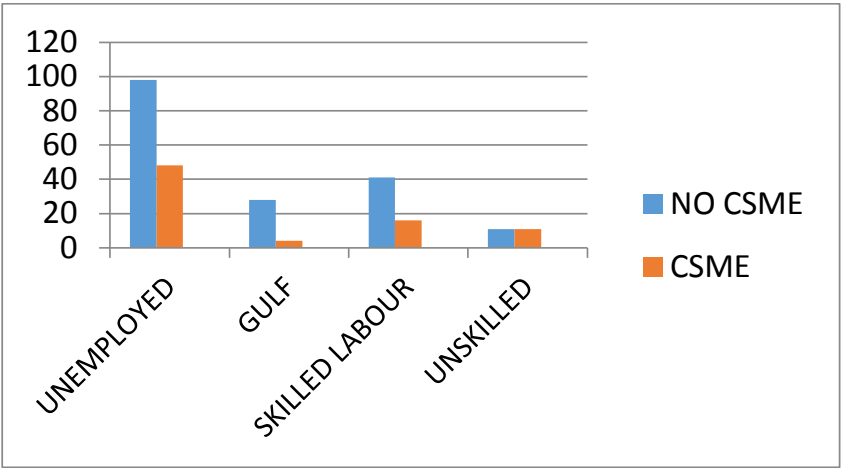

It was observed from the above graph that majority of patients fall in the unemployed group (146 patients), among which $32.9 \%$ had CSME .Also that in the better employed groups of gulf employees and skilled labour the rate of CSME was significantly lower accounting for $12.5 \%$ and $28.1 \%$ respectively. To be noted is the fact that even though in our sample unskilled group had only 22 patients, of which $50 \%$ of them had CSME.

Fig 6. Socioeconomic Status and Diabetic Retinopathy

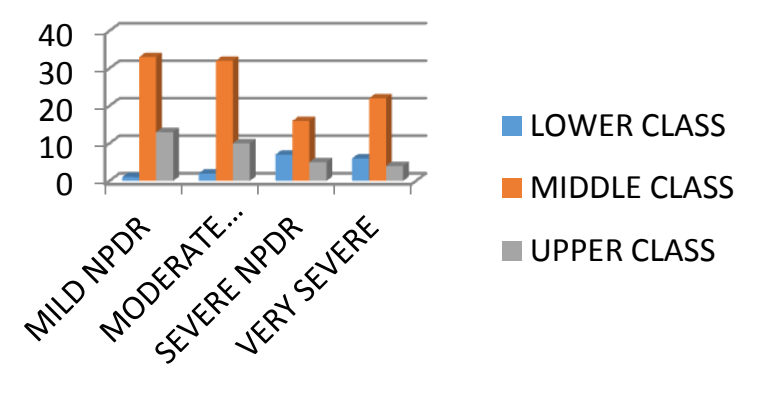

It was observed that the major number of patients had no diabetic retinopathy $(27.2 \%)$, followed by mild non proliferative retinopathy (NPDR) $18.3 \%$, moderate NPDR $17.1 \%$, very severe NPDR 12.5\%.High Risk PDR was 7.8\% and Advanced diabetic eye disease ( ADED ) $1.2 \%$. It was also Fig 7. Occupation and Diabetic Retinopathy
Fig 5.Socioeconomic status with CSME

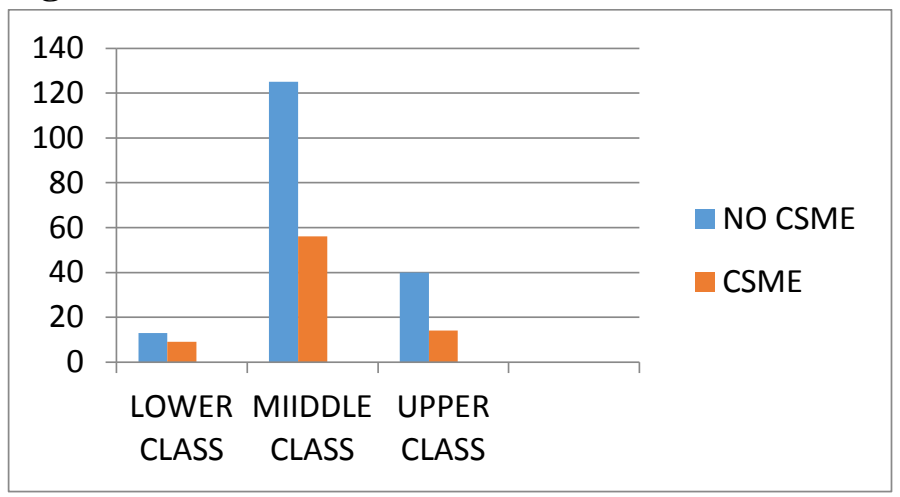

The number of patients with CSME is more in the middle class $(30.9 \%)$ and in the upper class 40 (74.1\%) had no CSME while 14 patients $(25.9 \%)$ had CSME. And this correlation of CSME with socioeconomic status showed an insignificant association with $\mathrm{p}$ value of 0.136 .

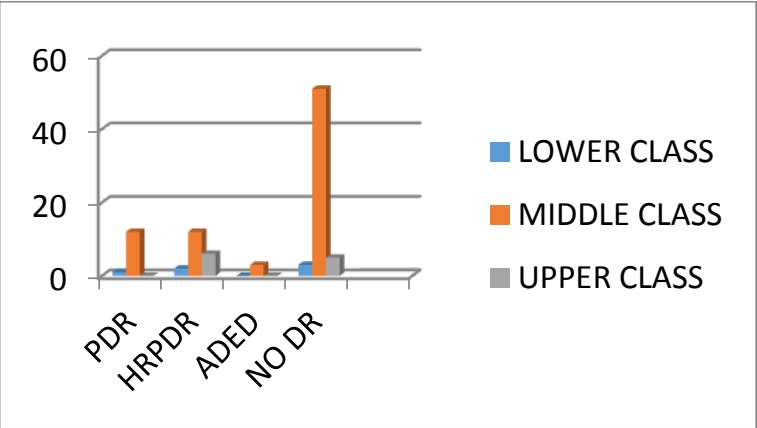

observed that severe $(31.8 \%)$ and very severe NPDR $(27.3 \%)$ was more in the lower socioeconomic class and respectively and PDR and ADED was notably absent in upper class. This association showed a significant $\mathrm{p}$ value of 0.022 .

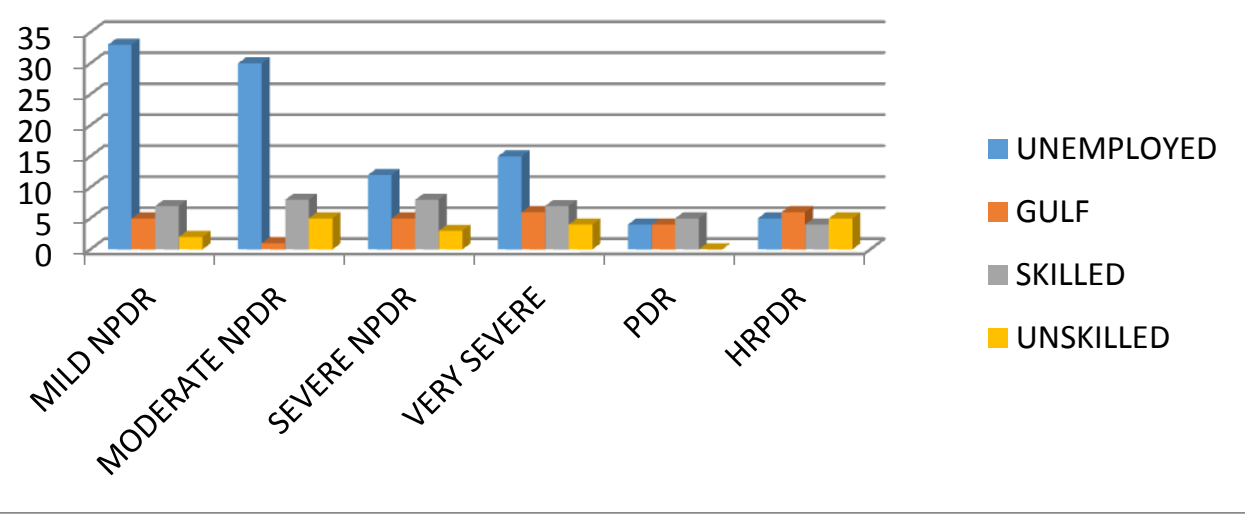


It was observed that out of the total 47 patients with mild NPDR, $22.6 \%$ belong to the unemployed category and in moderate NPDR, $20.5 \%$ belong to this group. As the severity of retinopathy increased, it was noted that $18.2 \%$ of the very severe NPDR and $22.7 \%$ of HRPDR belong to unskilled labour category.

\section{Discussion}

It has been observed that people from the deprived sectors of society were considered to be at greater risk of developing type 2 diabetes and their likelihood to experience multisystem complications from diabetes leading to significantly greater magnitude of morbidity and mortality was more than that of the affluent sectors of society. A variety of factors including malnutrition, lack of awareness of health issues, financial constraints and influence of various indigenous and quack remedies contribute to add on to the morbidity from this disease. Inspite of the various awareness programmes run by the government and other organisations, it is unfortunate that these facilities are inaccessible to a vast majority of population, especially those belonging to the lower socioeconomic strata of the society.

Various population based studies performed in India during the past 30years have indicated an increased prevalence of type 2 diabetes. In this study we had assessed the association of diabetic retinopathy with socioeconomic status, BMI, occupation and the place of residence.

In our study conducted among type 2 diabetic patients, it was observed that there was an increased prevalence of severe forms of diabetic retinopathy in the lower class of society with literally no proliferative retinopathy in the upper class. A population-based, cross-sectional observational study with longitudinal analysis over 12 years conducted at East of Scotland by Liying Low et al showed that socioeconomic deprivation was associated with increased prevalence of diabetic retinopathy in patients with type $1 \mathrm{DM}$, but not in patients with type $2 \mathrm{DM}^{(3)}$. In Spain, socioeconomic status was not independently associated with $\mathrm{DR}^{(4)}$. The fact that people belonging to the upper class were less affected could be due to the increased health awareness among patients and the readily accessible medical facilities so that they seek medical attention at the earliest than the people from deprived classes of the society.

Considering the impact of residence in the development of retinopathy, we have observed that more than three fourth of the study population come from rural areas highlighting the influence that place of residence and geographical factors have on the disease. Moreover the health facilities available to the rural people are limited and also the disease awareness level of these people are lower compared to the urban counterparts. But Litwin et al found no association between relative affluence of residence and presence of retinopathy at time of diagnosis of type $2 \mathrm{DM}^{(5)}$. One factor that explains the increased number of patients from rural areas in our study could be the fact that this study was conducted at government institute that is being predominantly utilised by the rural people and those belonging to the lower economic strata of the society. In our study $22.2 \%$ belonged to urban area while a study conducted at Sankara Nethralaya by Rajiv Raman et al showed that diabetic retinopathy had $18 \%$ prevalence in urban $\operatorname{areas}^{(6)}$.

As majority of our study population belonged to middle class with a statistically significant association with development of retinopathy, this can be attributed to the influence of economic factors and educational standards prevalent in these groups. Though our study does not directly measure the impact of educational qualifications of the patients, it can be inferred from the existing societal norms that socioeconomic status has a direct correlation with education. From a European perspective, the EURODIAB IDDM Complications study showed a higher prevalence of proliferative diabetic retinopathy in men with lower educational qualifications compared with those with higher levels of education ${ }^{(7)}$. 
Regarding the association of socioeconomic factors with CSME, it was noted that there was no significant association with the economic class, but there was remarkably lower rates of CSME noted among better employed groups and also that nearly $50 \%$ of unskilled labours had CSME. Also to be noted is the fact that patients with clinically significant macular edema report to the clinician earlier due to loss of central vision which profoundly affects their day to day activities and work.

It has been demonstrated from various studies that, though there have been significant improvements in the control and treatment of diabetes over the last decade, patients from socioeconomically underprivileged sections of society have benefited less than their more affluent counterparts ${ }^{(8,9)}$. The underlying cause for this disparity could be their ignorance about the disease or inability to turn up for routine check up and screening programmes due to financial problems. A study on socioeconomic status and complications of diabetes in young adults at Japan by Funakoshi et al showed that lower socioeconomic status was linked to greater likelihood of complications of diabetes mellitus ${ }^{(10)}$.

Also to be noted is the ongoing influence of allied counterparts of treatment and quack remedies which patients resort to for quicker and easier hyperglycaemic control without paying much attention to the underlying complications which this disease poses on the health system like retinopathy and nephropathy. Hence these people undergo various alternative treatment options until late stage, when ultimately all the possible damages would have already occurred to these organs resulting in irreparable organ damage and advanced diabetic eye disease leaving the patient blind. And it is at this stage that they seek authentic medical advice, but no much treatment options could be offered owing to the extensive damage.

\section{Conclusion}

The mechanisms by which socioeconomic deprivation translates into poorer clinical outcomes are unclear but may be related to the influence of education and its role in understanding of diabetes and its myriad complications, drug and follow up compliance, awareness of existing health facilities, accessibility to health care and financial burden which disease imposes. The incidence of complications seems to be less in the high socioeconomic strata as they are more aware and accessible to the health facilities.

Measures to provide timely health check up including diabetic retinopathy screening via telemedicine units and prompt referral from rural areas to tertiary ophthalmic centres with advanced facilities including laser therapy and also to ensure the follow up of these patients even after primary care should be made available. The current health programmes in India although gives importance to lifestyle diseases through its various non communicable disease awareness programmmes, the status of retinopathy screening still remains undeveloped.

Hence it is high time that government takes necessary actions to include retinopathy screening as a part of routine examination in the rural primary health centres and overcome the disparity which exists in the health care availability for the people irrespective of their socioeconomic and demographic differences.

\section{Limitation}

The comparison of these factors can be affected by the differences in measuring the socioeconomic status. Data compiled from self reported questionnaires and education may have reporting bias. Moreover our study has done a cross sectional collection of data from a tertiary government hospital which serves mainly the middle and lower class of the society. Hence the sample we have taken may reflect a higher number of these people and this may influence the outcome of our study.

Sources of Support: nil 


\section{Reference}

1. King H, Aubert RE, Herman WH. Global burden of diabetes, 1995-2025: prevalence, numerical estimates, and projections. Diabetes care. 1998 Sep 1;21(9):1414-31.

2. World Health Organization. Global report on diabetes. World Health Organization; 2016

3. Low L, Law JP, Hodson J, McAlpine R, O'Colmain U, MacEwen C. Impact of socioeconomic deprivation on the development of diabetic retinopathy: a population-based, cross-sectional and longitudinal study over 12 years. BMJ open. 2015 Apr 1;5(4):e007290.

4. Larranaga I, Arteagoitia JM, Rodriguez JL, Gonzalez F, Esnaola S, Pinies JA. Socio-economic inequalities in the prevalence of Type 2 diabetes, cardiovascular risk factors and chronic diabetic complications in the Basque Country, Spain. Diabetic Medicine. 2005 Aug 1;22(8):1047-53.

5. Litwin AS, Clover A, Hodgkins PR, Luff AJ. Affluence is not related to delay in diagnosis of Type 2 diabetes as judged by the development of diabetic retinopathy. Diabetic medicine. 2002 Oct 1;19(10): 843-6.

6. Raman R, Rani PK, Rachepalle SR, Gnanamoorthy P, Uthra S, Kumaramanickavel G, Sharma T. Prevalence of diabetic retinopathy in India: Sankara Nethralaya diabetic retinopathy epidemicology and molecular genetics study report 2. Ophthalmology. 2009 Feb 28;116(2): 311-8

7. Chaturvedi N, Stephenson JM, Fuller JH. The relationship between socioeconomic status and diabetes control and complications in the EURODIAB IDDM Complications Study. Diabetes care. 1996 May 1;19(5):423-30.

8. Yang SH, Chen SF, Nieh S, Liu CL, Lin YS, Lee CC, Lin FH. The Effect of
Individual and Neighbourhood Socioeconomic Status on Diabetes Mellitus Survival in Working Age Patients in Taiwan. PloS one. 2017 Jan 12;12(1):e 0169550

9. Osborn CY, De Groot M, Wagner JA. Racial and ethnic disparities in diabetes complications in the northeastern United States: the role of socioeconomic status. Journal of the National Medical Association. 2013;105(1):51.

10. Funakoshi M, Azami Y, Matsumoto H, Ikota A, Ito K, Okimoto H, Shimizu N, Tsujimura F, Fukuda H, Miyagi C, Osawa S. Socioeconomic status and type 2 diabetes complications among young adult patients in Japan. PloS one. 2017 Apr 24;12(4):e0176087. 